\title{
RARE EXTRA-ARTICULAR MANIFESTATION IN A PATIENT WITH RHEUMATOID ARTHRITIS: A CASE-REPORT
}

Lays Rosa Lindolpho1,*, Luiz Clovis Bittencourt Guimarães ${ }^{1}$, Letícia de Almeida Velasco², Letícia Maria Campo Dall'Orto de Almeida², Letícia Martins Paravidino², Letícia de Oliveira Barreto², Lhaylla Maria Peçanha Viana Farhat² ${ }^{2}$ Ana Luísa Miguel Marques²

1.Hospital Escola Álvaro Alvim, Campos dos Goytacazes (RJ), Brazil. 2.Faculdade de Medicina de Campos, Campos dos Goytacazes (RJ), Brazil.

*Corresponding author: laysrlindolpho@gamail.com

\section{BACKGROUND}

Rheumatoid arthritis (RA) is a chronic inflammatory disease that can affect several joints. It has a higher rate in women than in men, affecting people between 30 to 50 years old. It often presents as polyarthritis with peripheral, symmetrical, additive involvement with a predilection for the small joints of the hands and feet. The inflammatory process can expand into systems and organs, causing extra-articular manifestations.

\section{CASE REPORT}

Male patient, 65 years old, from Campos dos Goytacazes (RJ) sought the rheumatology clinic referred by the hematology clinic for clinical condition of thrombocytosis and arthralgia. Complained of history of polyarthritis for 2 years, involved symmetrically in large and small joints (hand, metacarpophalangeal, wrists, ankles and elbows). The polyarthritis was associated with morning stiffness and important weight loss (approximately $8 \mathrm{~kg}$ in 4 months). The patient denied skin lesions, fever, gastrointestinal disorders. Examination: signs of active arthritis, pain on fist palpation, proximal interphalangeal and metacarpophalangeal with bilateral edema and hyperemia. Improvement was seen on the polyarthritis condition using anti-inflammatory, glucocorticoid and hydroxychloroquine. In one month, he presented swollen and tenderness calves, suggesting deep venous thrombosis, submitted to Doppler ultrasound was diagnosed with Baker's cyst rupture. The main hypotheses suggested were essential thrombocythemia and active RA. Facing negativity of JAK2V617f mutation, diagnosis of RA was established from abnormal titer of autoantibodies against cyclic citrullinated peptide (anti-CCP) with a value of $251 \mathrm{U} / \mathrm{mL}$. The blood count result showed thrombocytosis $(1,697,000$ platelets $/ \mathrm{mm}^{3}$ ), hematocrit of $37 \%$ and leukocytes of $22,000 \mu \mathrm{L}$, Latex value was 32 (negative Waaler-Rose test), CCP $=251 \mathrm{U} / \mathrm{mL}$. Since then, the patient has been under methotrexate, hydroxychloroquine and folic acid treatment. There was an improvement of clinical manifestations after a year. Examination: hematocrit of $42 \%$ and leukocytes of $10,800 \mu \mathrm{L}$, C-reactive protein $=48 \mathrm{~mm}$, Latex $=512$ (Waaler-Rose test), speed of sedimentation of blood $=13 \mathrm{~mm}$ and platelet count within normal standards. Thus, the use of methotrexate was sustained along with rheumatological follow-up.

\section{CONCLUSION}

The thrombocytosis presented by the RA patient, in this case, draws attention for being a rare MEA, since a study reported that from 262 RA patients, only 4\% showed hematological manifestations, which are crucial for the differential diagnosis between RA and hematological pathologies. The RA treatment is a continuous process that requires constant monitoring of the patient , assessment of the disease activity index, monitoring of side effects, evaluation of the patient's functional capacity and investigation of extra-articular manifestations. 